\title{
BITE FORCE AND BONE HEIGHT CHANGES AROUND ABUTMENTS RETAINING MANDIBULAR REMOVABLE PARTIAL DENTURE WITH WROUGHT WIRE AND POLYAMIDE CLASPS: SPLIT MOUTH STUDY
}

\author{
Ahmed Khalifa Khalifa* and Nesreen Elmekawy **
}

\begin{abstract}
Objectives: This research highlights on the effect of polyamide clasp on the bone height changes of the abutment teeth and the bite force change comparing to conventional wrought wire clasp in a split mouth study.

Materials and Methods: This split mouth research was carried out on 14 partially edentulous participants with mean age (61.14) year. For every participant, a resin bilateral distal extension removable partial denture was constructed to be retained by a wrought wire clasp on one side and a polyamide clasp on the other. Standardized digital periapical radiograph was used to evaluate the abutment alveolar bone height change after 12 and, 18 months from denture insertion. Bite force transducer was used to measure the bite force for both clasp types sides at insertion and after 18 month of follow up.
\end{abstract}

Results: At comparing bone height change after insertion with the baseline, there was a significant increase in the bone resorption with the polyamide clasp after 18 month in mesial and distal aspect ( $p=0.01$ and 0.04 respectively); and after 12 month at mesial side $(p=0.01)$. There is also a significant difference in bone height change around abutments carry both clasp types at 12 and 18 months in distal side ( $p=0.03$ and 0.001 respectively); and in the mesial side ( $p=0.02$ and 0.01 respectively). The evaluation of the bite force revealed significant difference between measurements at time of insertion and 18 months of for polyamide and wrought clasp sides $(\mathrm{p}=$ 0.02 and 0.043 respectively).

Conclusion: This study results illustrated that both types of clasps were appropriate to be used with the acrylic removable partial denture as their influence on the abutment alveolar bone resorption is within the acceptable range of bone resorption. While there is a nonrelated-clasp type improvement in bite force.

* Lecturer of Removable Prosthodontics, Faculty of Dentistry, Mansoura University, Egypt.

** Associate Professor of Removable Prosthodontics, Faculty of Dentistry, Mansoura University, Mansoura, Egypt 


\section{INTRODUCTION}

Restoration of the missed teeth is important for dental arch integrity. This importance increases to include restoration of mastication, esthetic and phonetics for patients with long distal edentulous spans. Due to bad state and/or limited number of abutments, removable partial denture (RPD) may be the optimum solution. ${ }^{1}$

Appropriate design, in cases with long edentulous span RPD, is crucial for convenient force distribution and avoidance of excessive loading of the abutment tooth periodontal ligament (PDL). ${ }^{2}$ Bone surrounding abutment is affected by the axial and non-axial forces applied from retainers. ${ }^{3}$ Different methods were investigated to control the load delivered from long distal edentulous span RPDs to both teeth and residual ridges. These methods include reducing the load, distributing the load between teeth and residual ridges, and distributing the load widely. ${ }^{4}$ The main goal of the clasp design is to preserve the abutment rather than weaken the surrounding peridontium. ${ }^{5}$

One of the other great challenging at designing RPD is to restore esthetic not to impair it by using metallic retainers. ${ }^{1}$ The retainers are considered effective form biomechanical point of view but pessimistic for patients from the esthetic perspective. ${ }^{6}$ To partially overcome the problem of metallic retainers display, prosthodontists locate the clasp arm deeply close to gingiva to be camouflaged during smiling and speaking. ${ }^{7}$ Thus, a flexible nonrigid acceptable clasp from wrought wire is used in this apical undercut. ${ }^{8}$ The wrought wire clasps are popular form of partial prosthetic restoration. The surveys indicate that even up to $70 \%$ dentists prefer to use wire clasps. ${ }^{9}$

The new trend of using thermoplastic resins clasps is another way to get the advantages of retainers without esthetics drawbacks. ${ }^{10}$ Polyamide is used to create types of partial denture able to achieve the requirements for retention, support and stability with pleasant aesthetics than metal counterparts. ${ }^{11,12}$ Polyamide resins gained popularity and acceptance as a clasp material in clinical practice due to their flexibility and highly elastic nature that eventually decreases stress on the abutment teeth. ${ }^{13}$ The name for RPDs using polyamide is commonly known as non-clasp dentures, clasp-free dentures, and metalfree dentures. ${ }^{14}$ The resin part extends from the denture base to encircle abutment and responsible for retention should be called a clasp..$^{15}$ So, the term "non-clasp" is therefore inappropriate for PRD with nylon clasps. ${ }^{16}$

Utilization of metal-free materials RPD has many advantages over RPD made of metal as they have higher elasticity, improve esthetics due to their color and translucency with low water sorption and solubility. ${ }^{17,18}$

At conducting a clinical study, the standardization of cases is an illusion due to variation among patients. Other obstacles are the number of cases in each compared group which in turns reflects on the duration of the follow up and the cost of research work. The split mouth is a clinical trial in which each subject receives greater than or equal to two treatments, each to a separate section of the mouth. In split mouth research study, one side is considered the control for the study side. Beside, split mouth study eliminates the bias at randomization or selection of cases and gives clear results without multiple cofounders due to patients' conditions. The attractiveness of the split mouth design is that it removes a lot of inter-individual variability from the estimates of the treatment effect. ${ }^{19}$

This research highlighted the effect of polyamide clasp on the bone height changes of the abutment teeth and, the bite force change comparing to conventional wrought wire clasp in a split mouth study. The null hypothesis that there is no different in bone height level surrounding abutment of both clasp types; and the bite force in both sides after RPD insertion. 


\section{MATERIALS AND METHODS}

This split mouth research was designed to study acrylic RPDs in which one side of the denture were retained by wrought wire clasps ( $0.9 \mathrm{~mm}$ diameter $)$ and the other side retained by polyamide clasps.

\section{Study population}

This study was carried out on 14 participants with age group ranged between 55 - 68 years, (mean age 61.14 year; 9 males and 5 females). These participants were chosen according the following eligibilities: They were healthy with no systemic diseases achieved by physician, They had a good oral hygiene and upper completely edentulous arch against mandibular bilateral posterior edentulous span. (fig.1). Periodontal conditions of the remaining teeth were healthy and the crown-root ratio of the abutment was more than 1: 1 .

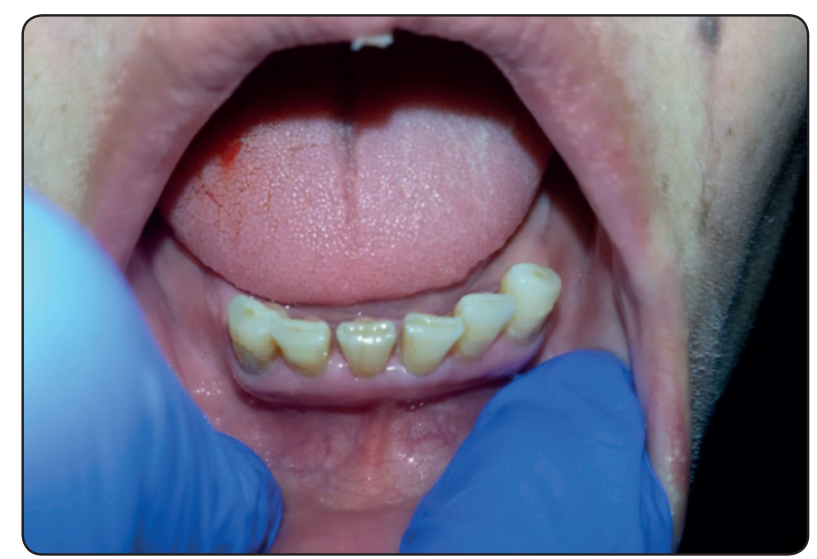

Fig. (1) Mandibular bilateral long edentulous spans posterior to the canines

\section{Ethical approval}

All study steps were explained to participants who were asked to sign informed written consents. The study protocol and methods were approved by Dental Research Ethical Committee of faculty of dentistry, Mansoura University under number (51217).

\section{Randomization}

While the study is split mouth, we randomized the side (right or left) of clasps to avoid the effect of patients' favorable chewing side if exists. Patients' names were listed on Excel sheet (Microsoft, USA) and sorted randomly for two groups; the first seven patients received the nylon clasp on the right side while the rest of participants received nylon clasp on left side.

\section{Pre-Prosthetic Procedures}

All participants were examined clinically and radiographically to assure inclusion criteria. Panoramic and periapical radiograph for abutments were captured to assure crown-root ratio. Periodontal therapies (scaling / pocket eradication) were done.

\section{Prosthetic Procedures}

Tentative maxillomandibular relation was done by the prepared primary casts on mean value articulator to analyze the occlusal plane of the remaining teeth. After plane correction, maxillary and mandibular final impressions were made and poured in dental stone (Dental stone, SuperCal IV, COE laboratories Inc., USA.) to produce master casts. Mandibular master cast was surveyed by dental surveyor (The Ney Surveyor: The T.M. Ney Co. Hartford.) to determine the survey line of abutments and blocking out of the undesired undercut by wax (Ney undercut wax, The T. M. Ney Co., Bloomfield. Conn.). The free gingival margins, covered by nylon clasp were relieved by blue inlay wax (Elkods, Egypt). Duplication of master cast was done with Type IV stone (Roko ${ }^{\circledR}$, Poland). Maxillomandibular relationship was registered; maxillary cast was mounted on the semi-adjustable articulator (Dentatus International, ARLS, Hagersten) with the aid of face-bow record and interocclusal record for mandibular model. Artificial teeth (Acrostone, Egypt) were modified for mechanical means of retention with the nylon denture base. After teeth modification, they were setting according to the lingualized occlusion concept, waxing up. Then; the lab will return the partial dentures for a full wax try-in. 


\section{Clasps fabrication}

After clinical try-in of the denture, a wrought wire clasp (0.9 mm diameter) was adapted to the abutment tooth as follow: the clasp starts at the lingual side and passes along the proximal surface of the abutment tooth to engage buccal undercuts. It passes 3-4 $\mathrm{mm}$ away from the proximal surface of abutment tooth then it lute to the master model to be embedded in the final denture base as it retain by mechanical means. For nylon clasp, the waxing up was extended from the trial denture base to the survey line of the abutment covering the relived free gingival margin.

\section{Denture processing}

Waxed mandibular dentures were sprued, invested in a special flask (Roko flask, USA) for the washing of the wax by hot water, utilize Multipress machine (MULTIPRESS ${ }^{\circledR}$ Moulding Machine, Roko $^{\circledR}$, Poland) programmed to the thermoplastic nylon material $\left(\mathrm{ACRON}^{\circledR}\right.$ - Thermoplastic Nylon , Roko $^{\circledR}$, Poland). The injection disposable cartridge was loaded by the clear polyamide which inject into the mold at $280^{\circ} \mathrm{C}$ at an appropriate pressure and temperature. The processed RPD was deflasked, finished and, polished ${ }^{\mathbf{1 2}}$ (fig.2). Before denture delivery; fine occlusion adjustment was done intraorally. Follow-up visits for radiographic assessment were arranged

\section{Evaluation of Abutment Alveolar Bone Height}

Immediately, after 12 and, 18 months from denture insertion standardized digital periapical radiographs were performed to each abutment tooth by customized positioning jig ${ }^{(20)}$. Alveolar bone height change of abutments teeth were estimated by using Corel draw 11 (Corel Co. USA) according to Abd ElKhalek et al.,, ${ }^{\mathbf{4} 21}$. Reference lines were traced to assess the abutment bone height changes as the following: vertical line (A) represents long axis of the abutment; and two horizontal lines $(\mathrm{C} \& \mathrm{~B})$ represent the mesial and distal cement-enamel junction of the abutment. Reference contact points(d $\& b)$ were the highest points of the mesial and distal interdental alveolar bone of the abutment respectively. The change in the length of (cd) and (ab) perpendicular lines were measured to estimate the bone level change measially and distally; while (a \& c) points located on (B and C) lines. (fig.3)

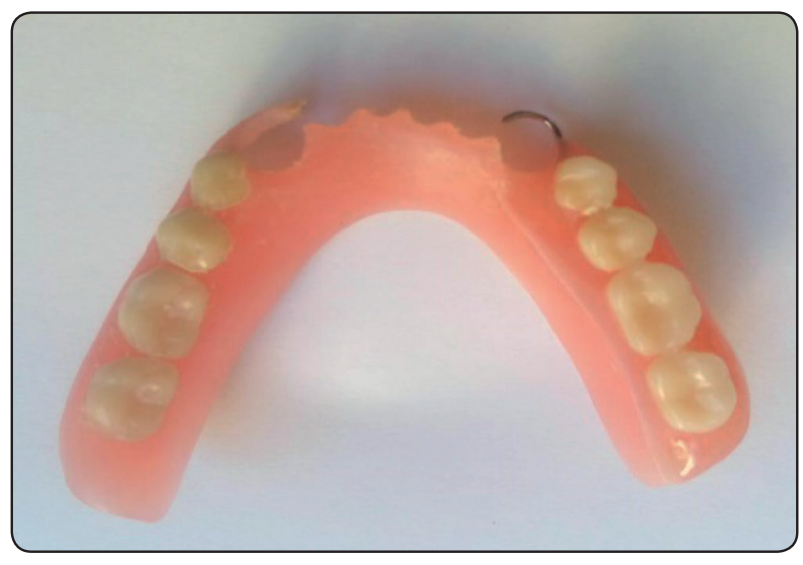

Fig (2) Finished acrylic removable partial denture with wrought wire clasp at the right side and polyamide clasp at the left side.

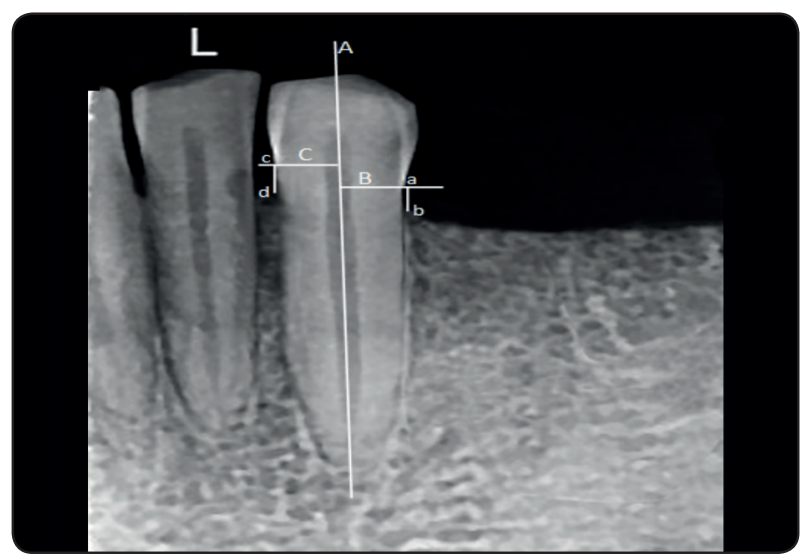

Fig. (3) Periapical $X$ ray with references lines \& points for measuring abutments alveolar bone height .

\section{Evaluation of Bite Force}

Bite force transducer (GM10 Occlusal ForceMeter; Nagaro Keiki, Tokyo, Japan) was used to measure the bite force for both clasp types sides at and after 18 month of insertion. The participant was in upright position with Frankfort-plane parallel 
to the floor. Each participant informed to bite on the plastic sheath covering the digital hydraulic pressure gauge and a vinyl biting element. Each participant performed three bites on each side (right and left), alternately. The pressure gauge displayed the bite force values in Newton on the digital screen. The arithmetic means of all measurements were calculated.22

\section{Statistical analysis}

The data of both abutment alveolar bone height and bite force were collected and analyzed by IBM SPSS v.23.0 software package (IBM SPSS Inc.). The data analyzed for normality by Shapiro-Wilk test. Comparison between the study observational periods of the study was done by paired t test at significant level when $p$ value $<.05$.

\section{RESULTS}

Comparison of abutment alveolar bone height at distal and mesial side for both clasp types after 12 and 18 months of insertion are represented in table 1. It was a significant bone height change around the abutment of wrought wire to polyamide clasp after 12 month and 18 months $(\mathrm{p}=0.03$ and 0.001 respectively). In the mesial side, there is also a significant bone height change around the abutment of both clasps after 12 month and 18 months ( $\mathrm{p}=$ 0.02 and 0.01 respectively). Within the polyamide clasp, there was a significant different in the distal bone level at and after 18 of insertion ( $\mathrm{p}=0.04)$; while there was a significant different in the mesial bone level at and after 12 and 18 months of insertion ( $p=0.01$ and 0.001 respectively).

TABLE (1) Comparing mesial and distal bone level for both clasp types after 12 and 18 months from denture insertion with the baseline bone level by paired t test

\begin{tabular}{|c|c|c|c|c|c|c|c|c|c|c|}
\hline & \multicolumn{4}{|c|}{ Abutment Distal side } & \multicolumn{2}{c|}{$\mathrm{p}$} & \multicolumn{2}{c|}{ Abutment Mesial side } & \multicolumn{2}{c|}{$\mathrm{p}$} \\
\hline Month & $\begin{array}{c}\text { At denture } \\
\text { insertion }\end{array}$ & $\begin{array}{c}12 \\
\text { months }\end{array}$ & $\begin{array}{c}18 \\
\text { months }\end{array}$ & 0 vs.12 & 0 vs.18 & $\begin{array}{c}\text { At denture } \\
\text { insertion }\end{array}$ & $\begin{array}{c}12 \\
\text { months }\end{array}$ & $\begin{array}{c}18 \\
\text { months }\end{array}$ & 0 vs.12 & 0 vs.18 \\
\hline Polyamide clasp & $3.2 \pm 1.2$ & $3.8 \pm 1.3$ & $4.3 \pm 1.4$ & 0.72 & $0.04 *$ & $2.6 \pm 0.9$ & $2.8 \pm 0.8$ & $3.2 \pm 1.1$ & $0.01 *$ & $.001 *$ \\
\hline $\begin{array}{c}\text { Wrought Wire } \\
\text { clasps }\end{array}$ & $3.4 \pm 1.1$ & $3.6 \pm 0.9$ & $3.6 \pm 1.3$ & 0.52 & 0.23 & $2.4 \pm 1.1$ & $2.4 \pm 1.3$ & $2.5 \pm 1.2$ & 0.076 & 0.06 \\
\hline $\mathrm{p}$ & & $0.03^{*}$ & $0.001^{*}$ & \multicolumn{1}{|c|}{} & & & $0.02^{*}$ & $0.01 *$ & & \\
\hline
\end{tabular}

$P$ significant at $\geq 0.05$

TABLE (2) Comparison of bite force $(\mathrm{N})$ for both clasp types at insertion and after 18 month of follow up by paired $t$ test.

\begin{tabular}{|c|c|c|c|}
\hline & $\begin{array}{c}\text { Polyamide } \\
\text { clasp }\end{array}$ & $\begin{array}{c}\text { Wrought wire } \\
\text { clasp }\end{array}$ & $\mathrm{p}$ \\
\hline $\begin{array}{c}\text { At denture } \\
\text { insertion }\end{array}$ & $118.67 \pm 22.53$ & $119.67 \pm 12.73$ & 0.71 \\
\hline 18 months & $138.81 \pm 29.08$ & $127.89 \pm 19.57$ & 0.65 \\
\hline $\mathrm{p}$ & $0.02 *$ & $0.043^{*}$ & \\
\hline
\end{tabular}

$P$ significant at $\geq 0.05$
Table 2 and figure 4 revealed comparison of bite force for both clasp types at denture insertion and after 18 month of follow up. Although the value of the bite force increased by the time elapsed, it was Non significant change in bite force between the side with wrought wire versus the polyamide clasp sides at denture insertion and after 18 months of follow up. While comparing the bite force increased significantly at the side with polyamide clasp from time of denture insertion to the 18 month after insertion $(\mathrm{p}=0.02)$. Also, at the side with wrought wire clasp the bite force increased significantly $(\mathrm{p}=0.043)$ 


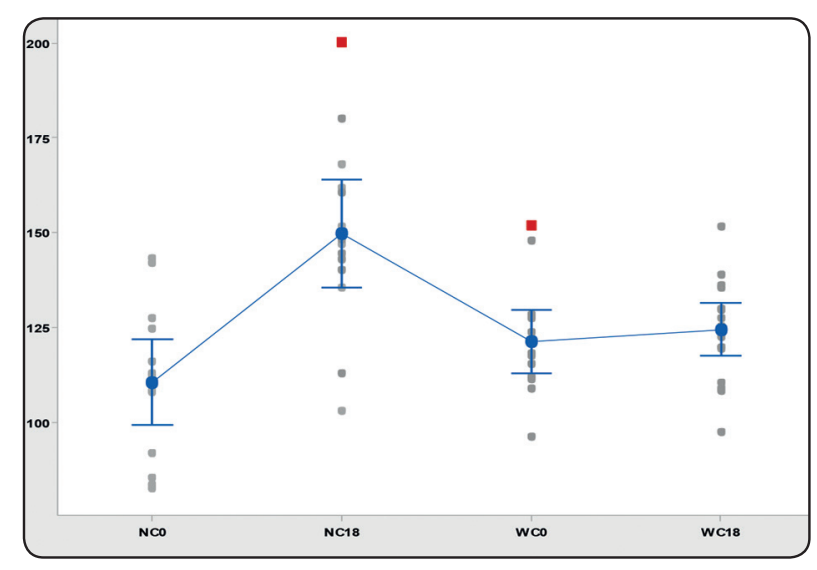

Fig. (4) Bite force (N) for both clasp types at insertion and after 18 month of follow up.

$\mathrm{NC} 0=$ nylon clasp side at insertion

NC18 = nylon clasp side after 18 month

$\mathrm{WC} 0=$ wrought wire clasp side at insertion

WC18= wrought wire clasp side after 18 month

\section{DISCUSSION}

This study compared the effect of two different flexible clasps on the abutment bone level change and bite force of the patient. To avoid the bias due to the natural variations among included cases, split mouth study design was conducted. The splitmouth research is designed as two interventions are assigned randomly to either the right or left halves of the dentition. The attractiveness of the split-mouth design is that it expunges most of inter-individual variability from the estimates of the treatment outcome. ${ }^{19}$

Wrought wire is considered an esthetic clasp. The structure and the design of the clasp allows the dentist to engage the deeper buccal and proximal undercut of the abutment close to the free gingival margin which camouflage the metal display. ${ }^{23}$ While, in some cases as high lip line or gingival smiling patients, the wrought wire and other metallic clasps make a great challenge for the esthetic design of RPD. ${ }^{24}$ Thus, claps constructed form the nylon materials is a recent solution to overcome the clasp display problems. ${ }^{25}$
The result revealed significant difference between bone resorptionin both mesial and distal aspects for abutment with wrought wire clasp and nylon clasp after 12 and 18 months of follow up. This may be due to the variation of stresses on abutment of RPD with the altering the clasp material ${ }^{26}$ or design. ${ }^{27}$ The bone height around abutment for wrought wire clasp revealed less bone loss comparing to abutment for nylon clasp. This may be explained by the flexibility and round cross section of the wire clasp. The wire clasp engages a deeper undercut due to its high proportional limit. ${ }^{8}$ In other study; wrought wire clasp showed less stiffness comparing to other types of clasps. ${ }^{28}$ The resulted bone loss due to stresses of wire clasp may be due to the shorten length of the clasp on the buccal aspect of the premolars. The more the length of the wrought wire clasp is the more flexible and less stress on abutment. ${ }^{29}$

The flexibility of the clasp also has a significant action on the distribution of the force. Non-rigid retainers cannot effectively distribute forces applied on abutment. ${ }^{30}$ This uncontrolled force distribution may lead to greater load on the residual ridge, which can interprets our finding as the distal bone level showed more bone loss than mesial side and the progress of distal bone loss with both clasp designs. ${ }^{20}$

Interestingly, the observed vertical movement of the denture base retained by non-rigid retainer toward the residual ridge was associated with a buccal micro movement of the abutment tooth. ${ }^{30}$ This suggests that the stress-breaking action of the flexible clasp, which was supposed to protect the abutment teeth from excessive forces, does not act properly. Over all, the flexibility of both wire and nylon clasps on the contrary of rigid direct retainer has little potential to reduce loads on both the abutment tooth and bone of the residual ridge. ${ }^{31}$

On the contrary to the wire clasp, the result revealed a significant bone loss in the mesial side of the abutment after a year from denture insertion. 
This considers the accelerated rate of bone change with the nylon clasp. One of disadvantages of nylon clasps is not resistant to abrasion and scratches. ${ }^{32}$ Thus, it is liability for easily attached bacteria and fungi molecules in saliva which causes the color change. This can initiate the process of formation of microbial colonies on nylon clasp. ${ }^{33}$ The adherence of microbial colonies to the clasp increases the liability of inter-dental mucosa and bone to in contact to bacterial toxins which are the main cause of periodontal diseases and expected bone resorption. ${ }^{34}$

In general, the result of bite force in this study is within the same range of previous study recorded the bite force with different prosthetic restorations. ${ }^{35}$ It is of interest that biting abilities improve immediately after insertion of prostheses. Although there is a debate about the time elapsed to reach the maximum biting ability after oral restoration, there is a confirmation about the significant improvement of biting ability with RPD. ${ }^{36}$ According to previous studies, the improvement of bite forces after denture restoration can be supported by evidences of increase masticatory muscle activity and, masticatory performance. ${ }^{37}$

In this research, there is a significant improvement of bite force for both types of clasp after 18 months of follow up comparing to the time of insertion. This is supported by the view that functional adaptation requires a time for settlement and reach the peak of function. ${ }^{36}$ The required time for maximum bite force improvement is to overcome, the instability and pain during chewing and biting for new prostheses act as limiting factors for the muscle action. ${ }^{38}$ While there was a slight increase in the maximum bite force within the side of nylon clasp. This could be interpreted by the increasing of tactile sense in this side due to more encirclement of the clasp to the abutment tooth. ${ }^{39}$

In this study the acrylic RPD was utilized as there were clinical evidence on the acrylic RPDs longevity, when viewed from a broad spectrum the survival percentages ranged between $86.3 \%$ to $100 \%$ for follow-up of five years or less. While; at time period between six to ten years this range grew to between $33.3 \%$ and $100 \%$ success. $^{40}$

\section{CONCLUSION}

In conclusion, this study results illustrated that:

- Acrylic Removable Partial Denture retained by both wrought wire and polyamide clasps have a high potential for the rehabilitation of long edentulous spans distal extension RPDs.

- Both types of clasps were appropriate to be used with the acrylic removable partial denture as their influence on the abutment alveolar bone resorption is within the acceptable range of bone resorption.

- Both types of clasps had a nonrelated-clasp type improvement in bite force.

\section{REFERENCES}

1. Petridis H, Hempton TJ. Periodontal considerations in removable partial denture treatment: a review of the literature. Int J Prosthodont. 2001; 14:164-72.

2. Frechette AR. The influences of partial den-ture design on distribution of force to abutment teeth. J Prosthet Dent. 2001; 85: 527-39.

3. Archangelo CM, Rocha EP, Pereira JA, Martin Junior M, Anchieta RB, FreitasJúnior AC. Periodontal ligament influence on the stress distribution in a removable partial denture supported by implant: a finite element analysis. J Appl Oral Sci. 2012; 20:362-8.

4. AbdEl.Khalik MM, El Mekawy NH, El-Kasaby SS. Mandibular kennedy class I partial denture management by broad stress distribution philosophy (radiographic assessment). J Indian ProsthodontSoc 2016; 16:282-7.

5. Prasad DK, Hegde C, Bardia A, Prasad DA. Questionable abutments: General considerations, changing trends in treatment planning and available options. J Interdiscip Dentistry $2013 ; 3: 12-7$.

6. Donovan TE, Cho GC: Esthetic considerations with removable partial dentures. J Calif Dent Assoc 2003; 31:551-55. 
7. Mourshed B, Al-Sabri FA, Qaed NA, Alaizari N, AlShamiri HM, Alfaqih A. Effect of clasp type and pullout location on clasp retention in different environment: In vitro study. Eur J Dent. 2017; 11:216-220.

8. ChrystieJA.Principles of clasp retention: a review. Australian Dental Journal 1988;33(2):96-100.

9. Fayyaz M, Ghani F, Appropriateness of knowledge and practices of dentists relating to using clasps in removable partial dentures, J. Ayub Med. Coll. Abbottabad., 2008, 20(1), 52-55.

10. Gomes S, Del Bel Cury A. Flexible resins: an esthetic option for partially edentulous patients. RGO, Rev Gaúch Odontol, Porto Alegre 2014;63: 81-86.

11. Singh K, Aeran H, Kumar N, Gupta N. Flexible thermoplastic denture base materials for aesthetical removable partial denture framework. J ClinDiagn Res. 2013;7:2372-3.

12. Hegazy S, Mekawy NE, El-Sheebany BE. In Vitro Comparative Study of Retention of Maxillary Kennedy Class I Removable Partial Denture Retained with Four Different Designs of Esthetic Clasps.PeriodonProsthodon. 2015, 1:1.

13. Kümbüloğlu Ö, Özkan Y K, Arda T, Özcan M. Retention and Deformation of CobaltChromium and High-Impact Polyamide Clasps. Meandros Med Dent J 2018;19:25-31

14. Vojdani M, Giti R. Polyamide as a Denture Base Material: A Literature Review. J Dent (Shiraz). 2015; 16:1-9.

15. Rickman LJ, Padipatvuthikul P, Satterthwaite JD. Contemporary denture base resins: Part 2. Dent Update. $2012 ; 39: 176-8$,

16. Fueki K, Ohkubo C, Yatabe M, Arakawa I, Arita M, Ino S, Kanamori T, Kawai Y, Kawara M, Komiyama O, Suzuki T, Nagata K, Hosoki M, Masumi S, Yamauchi M, Aita H, Ono T, Kondo H, Tamaki K, Matsuka Y, Tsukasaki H, Fujisawa M, Baba K, Koyano K, Yatani H. Clinical application of removable partial dentures using thermoplastic resin-part I: definition and indication of non-metal clasp dentures. J Prosthodont Res. 2014; 58:3-10.

17. Takabayashi Y. Characteristics of denture thermoplastic resins for non-metal clasp dentures. Dent Mater J 2010; 29:353-61.

18. Alla RK, Swamy R, Vyas R, Konakanchi A. Conventional and contemporary polymers for the fabrication of denture prosthesis: part I-overview, composition and properties. Int J Appl Dent Sci 2015; 1:82-9.
19. Lesaffre E, Philstrom B, Needleman I, Worthington H. The design and analysis of split-mouth studies: what statisticians and clinicians should know? Stat Med. 2009; 28:3470-82.

20. Degidi M, Nardi D, Piattelli A. Immediate versus one-stage restoration of small-diameter implants for a single missing maxillary lateral incisor: a 3-year randomized clinical trial. J Periodontol. 2009 ;80:1393-8.

21. Abd El-Khalek M, Aldeen MS, El Mekawy N. Stress releasing clasp assemblies design related to abutment alveolar bone resorption. Egypt Dent J 2006; 52:1785.

22. Al-Zarea BK. Maximum bite force following unilateral fixed prosthetic treatment: a within-subject comparison to the dentate side. Med Princ Pract. 2015;24(2):142-6.

23. Tran C, LaBarre E, Landesman HM. A removable partial denture using an esthetically designed round-rest distal clasp on maxillary anterior abutment teeth: A clinical report. J Prosthet Dent. 2009;102:286-9.

24. Beaumont Jr AJ. An overview of esthetics with removable partial dentures. Quintessence Int . 2002;33: 747 - 55.

25. Ito M, Wee AG, Miyamoto T, Kawai Y. The combination of a nylon and traditional partial removable dental prosthesis for improved esthetics: a clinical report. J Prosthet Dent. 2013;109:5-8.

26. Savitha PN, Lekha KP, Nadiger RK. Fatigue resistance and flexural behavior of acetal resin and chrome cobalt removable partial denture clasp: An in vitro study. Eur J Prosthodont 2015; 3:71-6.

27. Elsaih EA, Khalifa A K. in vitro load assessment of abutments in asymmetrical bilateral distal extension cases using different retainer designs. EGYPT DENT J 2015; 61:1937-1942

28. Morris HF, Asgar K, Tillitson E. Stress-relaxation testing. Part I: A new approach to the testing of removable partial denture alloys, wrought wires, and clasp behavior. J Prosthet Dent. 1981;46:133-41.

29. Naidoo LM. Guidelines for the use of wrought wire clasps for removable partial dentures.Master thesis, school of oral health science, university of the Witwatersand, johaesburg 2009.

30. Itoh H, Baba K, Aridome K, Okada D, Tokuda A, Nishiyama A, Miura H, Igarashi Y. Effect of direct retainer and major connector designs on RPD and abutment tooth movement dynamics. J Oral Rehabil. 2008; 35:810-5. 
31. Carr AB, McGivney GP, Brown DT. McCracken's Removable Partial Prosthodontics. 12th ed. St. Louis: Elsevier; 2010.p. 293.

32. McCabe F, Walls WG. Applied Dental Materials, $9^{\text {th }}$ ed. Blackwell, Publishing Ltd., Oxford 2008, pp. 110-120.

33. Ismiyati $\mathrm{T}$, Setyahadi S. Antifungal of Thermoplastic Nylon Denture Base Plate Incorporate with Nanoparticles High-Density Chitosan. J. Chitin Chitosan Sci. 2014; 2: 216-222.

34. Hienz SA, Paliwal S, Ivanovski S. Mechanisms of Bone Resorption in Periodontitis. J Immunol Res. 2015; 2015: $1-10$.

35. Miyaura K, Morita M, Matsuka Y, Yamashita A, Watanabe T. Rehabilitation of biting abilities in patients with different types of dental prostheses. J Oral Rehabil. 2000; 27:1073-6.
36. Shala K, Dula L, Pustina-Krasniqi T, Bicaj T, Ahmedi E, Lila-Krasniqi Z, Tmava-Dragusha A. Patient's Satisfaction with Removable Partial Dentures: A Retrospective Case Series. Open Dent J. 2016; 10:656-663.

37. Singh SK. Masticatory Efficiency of Partially Edentulous Patient 's Pre And Post Fixed Prosthodontic Rehabilitation. - JNDA 2015; 15: 18- 23.

38. Koc D, Dogan A, Bek B. Bite force and influential factors on bite force measurements: a literature review. Eur J Dent. 2010; 4:223-32.

39. Al-Jammali Z. Clinical Evaluation of Maximum Bite Force in Patient with Heat Cure acrylic and Flexible Partial Dentures .Med J Babylon 2017;14:509 - 517.

40. Verma R, Joda T, Bragger U, Wittneben JG. A systematic review of the clinical performance of tooth-retained and implant-retained double crown prostheses with a followup of $>/=3$ years. J Prosthodont. 2013 Jan;22(1):2-12. 